\title{
Infections with Neisseria gonorrhoeae and Chlamydia trachomatis in women with acute salpingitis
}

\author{
G B KRISTENSEN,* A C BOLlERUP,† K LIND, ₹ P-A MÅRH,§ P LADEHOFF,* \\ S LARSEN, * A MARUSHAK, * P RASMUSSEN, * J ROLSCHAU,* I SKOVEN,* \\ T S $\varnothing$ RENSEN,* AND I LIND† \\ From the *Department of Obstetrics and Gynaecology, University Hospital, Odense, the + Neisseria \\ Department, and the $¥$ Mycoplasma Laboratory, Statens Seruminstitut, Copenhagen, Denmark, and the \\ §Institute of Medical Microbiology, University of Lund, Sweden
}

SUMMARY The value of cultural and serological procedures in diagnosing gonococcal and chlamydial infections was investigated in 85 women who had provisional diagnoses of pelvic inflammatory disease. The correlation between certain clinical variables and the absence or presence of such infections was also studied. In 46 the diagnosis of acute salpingitis was verified by laparoscopy. The laboratory and clinical findings in the patients with acute salpingitis were compared with those in the remaining 39 women in whom laparoscopy did not show signs of inflammation. Salpingitis was considered to be gonococcal if Neisseria gonorrhoeae was isolated or a fourfold or more change in titre of antibodies to gonococcus pilus antigen was found. The diagnosis of chlamydial salpingitis was based on the isolation of Chlamydia trachomatis, a fourfold or more change in titre of IgG antibodies to or from a titre of $\geqslant 1 / 256$, or the presence of IgG antibodies at a titre of $\geqslant 1 / 512$. Patients with chlamydial salpingitis had less severe symptoms but a more protracted course of disease than patients with gonococcal salpingitis or with acute salpingitis not associated with the two pathogens.

\section{Introduction}

Several studies have shown that Neisseria gonorrhoeae and Chlamydia trachomatis are of aetiological importance in acute salpingitis. The proportion of cases attributable to these two agents varies partly with sociological differences between populations studied and partly with differences in clinical criteria used to select the patients investigated. ${ }^{1-5}$

This study was undertaken to investigate the value of serological tests and culture in diagnosing infections with $N$ gonorrhoeae and $C$ trachomatis in patients with acute salpingitis. The aim was also to ascertain whether the case history or clinical findings in patients with chlamydial salpingitis differed from those with gonococcal salpingitis or with acute salpingitis not associated with chlamydiae or

Address for reprints: Dr G B Kristensen, Department of Obstetrics and Gynaecology, University Hospital, DK-5000, Odense C, Denmark

Accepted for publication 7 November 1984 gonococci. These evaluations were based on findings in women who fulfilled clinical criteria for pelvic inflammatory disease (PID). ${ }^{6}$ The same clinical material has been used in an investigation of the importance of Mycoplasma hominis in acute salpingitis.?

\section{Patients and methods}

STUDY POPULATION

During one year 95 women who were admitted to a gynaecological department fulfilled a set of criteria for the provisional clinical diagnosis of PID. ${ }^{6}$ These criteria were acute lower abdominal pain and two or more of the following symptoms and signs: a rectal temperature higher than $38^{\circ} \mathrm{C}$, abnormal vaginal discharge, menstrual irregularities, vomiting, dysuria, pronounced tenderness of the pelvic organs on bimanual examination, a palpable adnexal mass or swelling, and an erythrocyte sedimentation rate of $\geqslant 15 \mathrm{~mm}$ in the first hour. In 85 women laparoscopy was performed on the day of admission. In 46 acute salpingitis was verified and graded as mild, moderate 
or severe according to the criteria proposed by Weström. ${ }^{8}$ Table I shows how many had received antibiotics before admission to hospital and the final diagnoses in 39 women with no laparoscopic signs of acute salpingitis. Ten women did not undergo laparoscopy because they had severe clinical symptoms, because anaesthesia could not be given at the time, or because they refused. These 10 women were omitted from evaluation. The patients were examined on the day of admission and once a week, including the day they were discharged. Thirteen women with, and 13 without, acute salpingitis had received treatment with a penicillin before admission to hospital, and one patient with acute salpingitis had received erythromycin (table I).

The schedule of antibiotic treatment of patients with acute salpingitis after admission to hospital comprised $1 \mathrm{MU}$ penicillin and $500 \mathrm{mg}$ streptomycin given intramuscularly twice a day for seven days and $1 \mathrm{~g}$ metronidazole suppositories twice a day for five days.

TABLE I Final diagnoses of 39 patients without acute salpingitis and treatment with antibiotics in all 85 patients before admission to hospital

\begin{tabular}{lll}
\hline & $\begin{array}{l}\text { No treated } \\
\text { before } \\
\text { admission } \\
(n=27)\end{array}$ & $\begin{array}{l}\text { Total } \\
\text { women } \\
(n=85)\end{array}$ \\
Final diagnoses & & \\
\hline No laparoscopic signs of current or & 0 & 2 \\
recent salpingitis: & 2 & 5 \\
$\quad$ Acute appendicitis & 3 & 10 \\
Ectopic pregnancy & 0 & 1 \\
Ovarian cyst & 3 & 7 \\
Retrograde menstrual bleeding & 5 & 14 \\
Hydrosalpinx or peritubal adhesions & 39 \\
No abnormal findings & 13 & 46 \\
Total & 14 & \\
\hline
\end{tabular}

\section{CULTURAL PROCEDURES}

On admission and again after one and two weeks or before the patient was discharged specimens for the isolation of $C$ trachomatis were collected from the urethra and the cervix on sterile, cotton tipped, alginate treated swabs (Calgiswab, Inolex, Glenwood, Illinois, USA). Specimens for the isolation of $\mathrm{N}$ gonorrhoeae were then taken from the urethra, the cervix, the rectum, and the fauces with sterile, cotton tipped, charcoal treated swabs.

The following specimens were obtained during laparoscopy. For the isolation of $N$ gonorrhoeae, exudate from the abdominal orifice of a fallopian tube was aspirated from 25 patients with acute salpingitis, and in seven a closed tube was punctured; in 22 patients without salpingitis the orifice was irrigated with $0.5 \mathrm{ml}$ sterile saline, which was then aspirated and transferred to a charcoal treated swab. For the culture of $C$ trachomatis a tiny biopsy specimen was taken from the fimbrial end of a tube from 21 patients with acute salpingitis and from 31 without salpingitis; material was obtained by puncture of a closed tube in six of the patients with acute salpingitis.

Swabs for the isolation of $N$ gonorrhoeae were transported by mail in Stuart's medium and cultured as described previously. ${ }^{910}$ The transportation time did not exceed 24 hours. Specimens for the isolation of $C$ trachomatis were immediately stored at $-80^{\circ} \mathrm{C}$ in a sucrose phosphate buffer and, after one to two months, cultured in McCoy cells treated with cycloheximide. ${ }^{11}$ The media contained newborn instead of fetal calf serum, which was not available.

\section{INVESTIGATION OF ANTIBODIES}

Antibodies to $N$ gonorrhoeae were investigated by an indirect haemagglutination test using gonococcus pilus antigen, ${ }^{12}$ and antibodies to $C$ trachomatis by a microimmunofluorescence test. ${ }^{13}$

At least two blood samples were taken from 45 patients with, and 29 without, acute salpingitis at intervals of one week. Only one blood sample was taken from 10 patients without salpingitis because they were discharged within a week. Seven had an ectopic pregnancy or a ruptured ovarian cyst, one had peritubal fibrous adhesions without signs of current infection, and two had normal adnexa at laparoscopy.

\section{STATISTICAL METHODS}

Non-parametric (Mann-Whitney, $\chi^{2}$ and Fisher's) statistical tests were used to evaluate differences, and $\mathrm{p}<0.05$ was considered to be significant. The predictive value of positive microimmunofluorescence test results for the presence of acute salpingitis was calculated from the formula of Wulff ${ }^{14}$ :

Patients with acute salpingitis with positive results all patients with positive results

and the formula:

Patients without salpingitis with negative results

$$
\text { all patients with negative results }
$$

was used to calculate the predictive value of negative microimmunofluorescence test results for the absence of acute salpingitis.

\section{Results}

CULTURE

$N$ gonorrhoeae was isolated from the cervix of six $(13 \%)$ patients with acute salpingitis and by puncture of a closed tube in one of these. It was not recovered 
TABLE II Titres of antibodies to gonococcus pilus antigen in serum of patients with and without acute salpingitis

\begin{tabular}{llllllllll}
\hline & \multicolumn{7}{l}{ No with maximum titre of antibodies to N gonorrhoeae of: } & \\
\cline { 2 - 8 } Diagnoses and results of culture & $<1 / 40$ & $1 / 40$ & $1 / 80$ & $1 / 160$ & $1 / 320$ & $1 / 640$ & $\geqslant 1 / 1280$ & Total \\
\hline Patients with acute salpingitis & 2 & 1 & 2 & & & 1 & 6 \\
$N$ gonorrhoeae isolated & 32 & 2 & & 5 & 1 & & 40 \\
$N$ gonorrhoeae not isolated & 34 & 3 & 2 & 5 & 1 & 1 & 0 & 46 \\
$\quad$ Total & 37 & 1 & & & 1 & & 39 \\
Patients without salpingitis* &
\end{tabular}

* $N$ gonorrhoeae not isolated.

from any patient who had received antibiotic treatment before admission to hospital.

$C$ trachomatis was isolated from the urethra or the cervix, or both, in $11(24 \%)$ patients with acute salpingitis, of whom two also harboured $N$ gonorrhoeae. $C$ trachomatis was isolated from only two $(14 \%)$ out of 14 patients with acute salpingitis who had been treated with antibiotics before admission to hospital, and from nine (28\%) out of 32 who had not. A tubal biopsy specimen was taken from five of the 11 patients with acute salpingitis and $C$ trachomatis in the cervix and an aspirate from a closed tube from one, but these specimens did not yield $C$ trachomatis. A second set of specimens, which all gave negative results, was taken from nine of these 11 patients a week later. One patient without salpingitis who had an ectopic pregnancy harboured $C$ trachomatis in the cervix.

\section{SEROLOGICAL TESTS}

Table II shows the results of tests for antibodies to gonococcus pilus antigen. A fourfold or more change in the titre of antibodies was seen in four patients with acute salpingitis, of whom one had received treatment with antibiotics before admission to hospital.

Table III shows the results of tests for IgG antibodies to $C$ trachomatis. A maximum titre of $\geqslant 1 / 256$ and $\geqslant 1 / 512$ was seen in $29(63 \%)$ and $24(52 \%)$ of patients with acute salpingitis and in nine $(23 \%)$ and three $(8 \%)$ of patients without salpingitis $(\mathrm{p}<0.01$ for both titres). Out of 11 patients with acute salpingitis who had positive cultures for $C$ trachomatis, 10 $(91 \%)$ had a maximum titre of $\geqslant 1 / 512$. A titre of $\geqslant 1 / 512$ was seen in three patients without salpingitis, all reporting a history of PID, whereas titres below $1 / 512$ were seen equally often in patients reporting and not reporting a history of PID.

If a microimmunofluorescence test for IgG antibodies to $C$ trachomatis was defined as giving a positive result at a maximum titre of $\geqslant 1 / 256$ or $\geqslant 1 / 512$, then the positive result would have predictive values for acute salpingitis of $76 \%$ $(60-89 \%)$ or $90 \%(71-98 \%)$ respectively (with $95 \%$ confidence limits in brackets). The predictive value of negative test results for the absence of salpingitis would be $64 \%$ (48-77\%) for a cut off point of $\geqslant 1 / 256$ and $62 \%(48-75 \%)$ for a cut off point of $\geqslant 1 / 512$. In women without a history of PID a titre of $\geqslant 1 / 512$ would have a predictive value of $100 \%$ (78-100\%) for current acute salpingitis.

In 14 patients with acute salpingitis a fourfold or more change in titre of IgG antibodies to $C$ trachomatis was seen, and in all cases the change was to or from a titre of $\geqslant 1 / 256$.

Table IV shows the results of tests for IgM antibodies to $C$ trachomatis. Maximum titres of $\geqslant 1 / 32$ and $>1 / 64$ were found in $15(33 \%)$ and $12(26 \%)$ patients with acute salpingitis and in four $(10 \%)$ and two $(5 \%)$ patients without salpingitis $(p<0.025$ for both titres). Out of the 11 patients with acute salpingitis who yielded positive cultures for $C$

TABLE III Titres of IgG antibodies to Chlamydia trachomatis in serum of patients with and without acute salpingitis

\begin{tabular}{|c|c|c|c|c|c|c|c|c|c|c|c|}
\hline \multirow[b]{2}{*}{ Diagnoses and results of culture } & \multicolumn{10}{|c|}{ No with maximum titre of $\operatorname{IgG}$ antibodies to $C$ trachomatis of: } & \multirow[b]{2}{*}{ Total } \\
\hline & $<1 / 16$ & $1 / 16$ & $1 / 32$ & $1 / 64$ & $1 / 128$ & $1 / 256$ & $1 / 512$ & $1 / 1024$ & $1 / 2048$ & $\geqslant 1 / 4096$ & \\
\hline $\begin{array}{l}\text { Patients with acute salpingitis: } \\
\text { C trachomatis isolated } \\
\text { C trachomatis not isolated }\end{array}$ & 10 & $\begin{array}{l}1 \\
1\end{array}$ & & 4 & 1 & 5 & $\begin{array}{l}2 \\
2\end{array}$ & $\begin{array}{l}3 \\
8\end{array}$ & $\begin{array}{l}2 \\
1\end{array}$ & $\begin{array}{l}3 \\
3\end{array}$ & $\begin{array}{l}11 \\
35\end{array}$ \\
\hline Total & 10 & 2 & 0 & 4 & 1 & 5 & 4 & 11 & 3 & 6 & 46 \\
\hline $\begin{array}{l}\text { Patients without acute salpingitis: } \\
C \text { trachomatis isolated } \\
C \text { trachomatis not isolated }\end{array}$ & 15 & $\begin{array}{l}1 \\
2\end{array}$ & 3 & 9 & & 6 & 1 & 2 & & & $\begin{array}{r}1 \\
38\end{array}$ \\
\hline Total & 15 & 3 & 3 & 9 & & 6 & 1 & 2 & & & 39 \\
\hline
\end{tabular}


TABLE IV Titres of IgM antibodies to Chlamydia trachomatis in serum of patients with and without acute salpingitis

\begin{tabular}{|c|c|c|c|c|c|c|c|c|}
\hline \multirow[b]{2}{*}{ Diagnoses and results of culture } & \multicolumn{7}{|c|}{ No of patients with maximum titre of: } & \multirow[b]{2}{*}{ Total } \\
\hline & $<1 / 16$ & $1 / 16$ & $1 / 32$ & $1 / 64$ & $1 / 128$ & $1 / 256$ & $>1 / 512$ & \\
\hline $\begin{array}{l}\text { Patients with acute salpingitis } \\
\text { C trachomatis isolated } \\
\text { C trachomatis not isolated }\end{array}$ & $\begin{array}{r}4 \\
24\end{array}$ & $\begin{array}{l}0 \\
3\end{array}$ & $\begin{array}{l}2 \\
1\end{array}$ & $\begin{array}{l}1 \\
2\end{array}$ & $\begin{array}{l}1 \\
2\end{array}$ & $\begin{array}{l}1 \\
2\end{array}$ & $\begin{array}{l}2 \\
1\end{array}$ & $\begin{array}{l}11 \\
35\end{array}$ \\
\hline Total & 28 & 3 & 3 & 3 & 3 & 3 & 3 & 46 \\
\hline $\begin{array}{l}\text { Patients without salpingitis } \\
\text { C trachomatis isolated } \\
C \text { trachomatis not isolated }\end{array}$ & $\begin{array}{r}1 \\
31\end{array}$ & 3 & 2 & 1 & & 1 & & $\begin{array}{r}1 \\
38\end{array}$ \\
\hline Total & 32 & 3 & 2 & 1 & & 1 & & 39 \\
\hline
\end{tabular}

trachomatis, seven $(64 \%)$ had a maximum titre of $\geqslant 1 / 32$ and five $(45 \%)$ a maximum titre of $\geqslant 1 / 64$.

If a microimmunofluorescence test for IgM antibodies to $C$ trachomatis was defined as giving a positive result at a maximum titre of $\geqslant 1 / 32$ or $\geqslant 1 / 64$, then this positive result would have predictive values for acute salpingitis of $79 \%(54-94 \%)$ or $86 \%$ $(57-98 \%)$, respectively. The predictive value of a negative test for the absence of salpingitis would be $53 \%(40-65 \%)$ for a titre of $\geqslant 1 / 32$ and $52 \%$ $(40-64 \%)$ for a titre of $\geqslant 1 / 64$.

Out of six patients with acute salpingitis who had a fourfold or more change in titre of IgM antibodies to $C$ trachomatis, five $(83 \%)$ showed a rise to $1 / 128$ or more, and one $(17 \%)$ to $1 / 64$. Five of these six patients had a concomitant change in the titre of IgG antibodies.

$C$ trachomatis was isolated from seven (47\%) out of 15 patients with acute salpingitis who had an appreciable change in titre of either IgG or IgM antibodies to $C$ trachomatis, from three (30\%) out of 10 patients with acute salpingitis who had stationary titres of $\operatorname{IgG} \geqslant 1 / 512$, and from one $(5 \%)$ out of 21 patients with acute salpingitis who had stationary titres of IgG below 1/512. In 32 patients who had not received antibiotic treatment before admission, $C$ trachomatis was isolated from five $(71 \%)$ out of seven who had an appreciable change in titre, from three $(38 \%)$ out of eight who had stationary titres of IgG $\geqslant 1 / 512$, and from one (6\%) out of 18 who had stationary titres of IgG below 1/512.

\section{RESULTS OF LABORATORY TESTS RELATED TO CLINICAL FINDINGS}

On the basis of the results described above, the patients with acute salpingitis were described as having gonococcal salpingitis if $N$ gonorrhoeae was isolated from the cervix, the urethra, or both, or if the titre of antibodies to gonococcus pilus antigen changed appreciably. The term chlamydial salpingitis was used if one of the following criteria was fulfilled: (a) $C$ trachomatis was isolated from the cervix, the urethra, or both; (b) a fourfold or more change in titre of $\mathrm{IgG}$ antibodies to $C$ trachomatis to or from $\geqslant 1 / 256$ was shown; or (c) an IgG antibody titre of $\geqslant 1 / 512$ was shown. The patients with acute salpingitis were described as having chlamydial and gonococcal salpingitis if one of both sets of criteria were present and as having non-chlamydial, nongonococcal salpingitis if none of them was present.

Table V shows the severity of disease observed on laparoscopy in the patients with these four types of acute salpingitis. The visible changes were more severe in patients with chlamydial salpingitis than in those with gonococcal salpingitis or non-chlamydial, non-gonococcal salpingitis, but the difference was not significant. In 10 patients with acute salpingitis who did not undergo laparoscopy and were not included in the evaluations, the infection was graded clinically as mild in eight cases and as severe in two. Three of these 10 patients had chlamydial salpingitis, two had chlamydial and gonococcal salpingitis, and five had non-chlamydial, non-gonococcal salpingitis.

Oral contraceptives were used by equal numbers of patients with the four types of acute salpingitis. More of those with chlamydial salpingitis (13/22 (59\%)) than with non-chlamydial, non-gonococcal salpingitis $(3 / 17(18 \%))$ were fitted with an IUCD $(p=0 \cdot 01)$. Factors predisposing for salpingitis, such as insertion of an IUCD, curettage, hysterosalpingography, abortion, and delivery within three months of admission to hospital were recorded in 15 patients, similar numbers of whom had the four

TABLE V Laparoscopic grading of tubal inflammation in women with chlamydial salpingitis (CS), chlamydial and gonococcal salpingitis (CS/GS), gonococcal salpingitis (GS), and non-chlamydial, non-gonococcal salpingitis (NC/NGS)

\begin{tabular}{lccccc}
\hline & \multicolumn{7}{c}{ No of patients with: } & \\
\cline { 2 - 5 } Degree of inflammation & $C S$ & $C S / G S$ & $G S$ & $N C / N G S$ & Total \\
\hline Mild & 5 & 0 & 2 & 9 & 16 \\
Moderate & 6 & 1 & 0 & 3 & 10 \\
Severe & 11 & 3 & 1 & 5 & 20 \\
Total & 22 & 4 & 3 & 17 & 46 \\
\hline
\end{tabular}


types of acute salpingitis. A history of PID was given by $19(41 \%)$ women with acute salpingitis, similar numbers of whom had the four types of acute salpingitis.

There was no difference in age between patients with acute salpingitis (median 25, range 17-39 years), and patients without acute salpingitis (median 24, range 15-38 years). Among the patients with acute salpingitis, those with chlamydial, gonococcal, or chlamydial and gonococcal salpingitis were appreciably younger than patients with nonchlamydial, non-gonococcal salpingitis, the median ages being $221 / 2,27,19$, and 27 years respectively. Patients with chlamydial salpingitis had experienced symptoms before admission to hospital for longer than patients with gonococcal or non-chlamydial, non-gonococcal salpingitis $(p=0.007)$, the median time being $7,7,1$, and 2 days respectively. Table VI shows that a rectal temperature of more than $38^{\circ} \mathrm{C}$ was less common among patients with chlamydial than those with gonococcal or non-chlamydial, nongonococcal salpingitis $(p=0.01)$, and an ESR $\geqslant 20 \mathrm{~mm}$ in the first hour was more common in patients with chlamydial salpingitis than in those with non-chlamydial, non-gonococcal salpingitis $(p=0 \cdot 05)$.

Perihepatitis with a fibrinous exudate on the surface of the liver or violin string adhesions to the diaphragm, or both, was seen in three out of 46 patients with acute salpingitis undergoing laparoscopy, although this condition was not looked for routinely. All three had severe salpingitis with pelviperitonitis and were diagnosed as having chlamydial salpingitis, but none of them had symptoms attributable to perihepatitis.

\section{Discussion}

In Denmark, most patients with acute PID are treated by general practitioners. Most patients admitted to hospital have pronounced symptoms or signs or a poor response to antibiotic treatment. To assess the value of cultural and serological procedures in diagnosing gonococcal and chlamydial infections, patients should be studied irrespective of previous

TABLE VI Some clinical variables in women with chlamydial salpingitis (CS), chitumydial and gonococcal salpingitis (CS/GS), gonococcal salpingitis (GS), and nonchlamydial, non-gonococcal salpingitis (NC/NGS)

\begin{tabular}{lllll}
\hline \multicolumn{5}{c}{ No of patients with: } \\
\cline { 2 - 6 } Clinical variables & $\begin{array}{l}C S \\
(n=22)\end{array}$ & $\begin{array}{l}\text { CS/GS } \\
(n=4)\end{array}$ & $\begin{array}{l}G S \\
(n=3)\end{array}$ & $\begin{array}{l}\text { NC/NGS } \\
(n=17)\end{array}$ \\
\hline Rectal temperature $>38^{\circ} \mathrm{C}$ & 3 & 1 & 3 & 10 \\
ESR $\geqslant 20 \mathrm{~mm}$ in first hour & 16 & 3 & 2 & 7 \\
\hline
\end{tabular}

antibiotic treatment or the duration of symptoms before admission to hospital. The group used for comparison should consist of women without acute salpingitis, but in whom this diagnosis has been considered, who match the patients with acute salpingitis for age and previous exposure to genital infections. ${ }^{14}$ In the study reported here this was achieved by using liberal criteria for a provisional diagnosis of PID in selecting the study group, and by later subdividing the patients into those with and without acute salpingitis according to laparoscopic findings.

Most cases of acute salpingitis are caused by micro-organisms ascending from the lower genital tract. It is not known whether, in individual cases of acute salpingitis, there is only one aetiological agent, which perhaps paves the way for a concomitant infection with one or more opportunist organisms. ${ }^{15}$ In this study we made no attempt to isolate aerobic or anaerobic bacteria other than $N$ gonorrhoeae and $C$ trachomatis from the genital tract. The possible role of $M$ hominis as an aetiological agent of acute salpingitis has been evaluated in the same study population, as reported separately. ${ }^{7}$

In Scandinavian studies $N$ gonorrhoeae has been isolated from the cervix or urethra, or both, in only small proportions $(5-26 \%)$ of patients with acute salpingitis, ${ }^{1-5}$ although this organism has been recovered from most patients with acute salpingitis in studies from the USA. ${ }^{15-17} N$ gonorrhoeae has been isolated from the tubes of five of 13 patients with acute salpingitis who were harbouring the microorganism in the cervix ${ }^{17}$ and from one of four in the present study.

$C$ trachomatis was isolated from $24 \%$ of all patients with acute salpingitis and from $28 \%$ of patients who had not received antibiotic treatment before admission to hospital. These figures were not appreciably different from the $38-47 \%$ reported by other Scandinavian workers using laparoscopy in diagnosing acute salpingitis. ${ }^{2-4} C$ trachomatis was isolated in fewer patients with acute salpingitis who had received antibiotics before admission to hospital than in those who had not. As reported by Bowie and Lee, ${ }^{18}$ antibiotic treatment may not eradicate the chlamydiae in a patient but may decrease the infectivity of the organisms in cell cultures. This may also partly explain the low rate of isolation of $C$ trachomatis in patients with acute salpingitis and serological indication of a current chlamydial infection. It may also be the reason that our culture positive patients yielded negative results after treatment with antibiotics while in hospital. Another explanation for the low rate of isolation of $C$ trachomatis was possibly our use of Calgiswab, which may reduce the number of inclusions in McCoy cell cultures. ${ }^{19}$ The use of newborn instead of 
fetal calf serum may also reduce the number of inclusions (Bollerup AC, unpublished observations). Mårdh et al have suggested that an immune response to $C$ trachomatis results in negative cultures, ${ }^{4}$ but in our study $C$ trachomatis was isolated from equal numbers of patients with low and high titres of IgM or IgG antibodies (tables III and IV).

Our attempts at isolating $C$ trachomatis from the fallopian tubes were not successful. Biopsy specimens taken from the fimbrial ends of the tubes may be less useful for culture than specimens obtained by rotating a cotton tipped swab inside the lumen of the tubes. ${ }^{20}$ Furthermore, tubal specimens could be obtained from only five patients with acute salpingitis who harboured $C$ trachomatis in the cervical canal, as such patients often had closed tubes. For these reasons the diagnosis of gonococcal and chlamydial salpingitis in many patients must rely on the results of culture from the lower genital tract and of serological tests.

Circulating antibodies to $C$ trachomatis may be present because of previous or recent chlamydial infection, whether restricted to the cervical canal or affecting the endometrium or the salpinges as well. In infectious diseases that have been protracted before blood samples are taken, high antibody titres may be stationary while the patient is under medical care. The possibility of showing a fourfold rise in titre and of isolating the pathogen may have passed. Some cases therefore escape detection if an appreciable rise in titre is accepted as the only serological criterion of current infection. Stationary titres may be included as a tool in clinical decision making, provided that a sufficiently high cut off point of antibody titres is chosen as a criterion of current infection and lower titres, which indicate past infection, are excluded. Thus a positive test may have a high predictive value.

Chlamydial IgM antibodies at a titre of $\geqslant 1 / 64$ were found in too few patients with acute salpingitis and a positive culture for $C$ trachomatis for the test to be used to diagnose chlamydial salpingitis.

The clinical course of chlamydial salpingitis was more insidious than gonococcal or non-chlamydial, non-gonococcal salpingitis, with less severe symptoms and a longer duration of illness before admission to hospital. At laparoscopy, however, the visible inflammation of the tubes was slightly more severe in patients with chlamydial salpingitis than in those with gonococcal or non-chlamydial, nongonococcal salpingitis. Similar findings have been reported in two other Scandinavian studies. ${ }^{21}$

Our findings confirm the importance of chlamydial infections in acute salpingitis. It is therefore recommended that treatment regimens should include antibiotics active against $C$ trachomatis.
This study was supported in part by grant No $552-967$ from the Danish Medical Research Council. We are grateful to Professor Dr J Ipsen and L Hansen for statistical help and advice.

\section{References}

1. Paavonen J. Chlamydia trachomatis in acute salpingitis. Am J Obstet Gynecol 1980; 138:957-9.

2. Gjonnaess H, Dalaker K, Anestad G, Mårdh P-A, Kvile G, Bergan T. Pelvic inflammatory disease: etiologic studies with emphasis on chlamydial infection. Obstet Gynecol 1982;59:550-5.

3. Osser S, Persson K. Epidemiologic and serodiagnostic aspects of chlamydial salpingitis. Obstet Gynecol 1982;59:206-9.

4. Mårdh P-A, Lind I, Svensson L, Weström L, Møller BR. Antibodies to Chlamydia trachomatis, Mycoplasma hominis, and Neisseria gonorrhoeae in sera from patients with acute salpingitis. British Journal of Venereal Diseases 1981;57:125-9.

5. Moller BR, Mărdh P-A, Ahrons S, Nüssler E. Infection with Chlamydia trachomatis, Mycoplasma hominis and Neisseria gonorrhoeae in patients with acute pelvic inflammatory disease. Sex Transm Dis 1981; 8: 198-202.

6. Jacobsen $L$, Westrom L. Objectivized diagnosis of acute pelvic inflammatory diseases. Am J Obstet Gynecol 1969;105: 1088-98.

7. Lind K, Kristensen GB, Bollerup AC, Lind I, et al. Importance of Mycoplasma hominis in acute salpingitis assessed by culture and serological tests. Genitourin Med 1985;61:185-9.

8. Westrom L. Effect of acute pelvic inflammatory disease on fertility. Am J Obstet Gynecol 1975; 121:707-13.

9. Lind I. Methodologic aspects of routine procedures for identification of Neisseria gonorrhoeae by immunofluorescense. Ann N Y Acad Sci 1975; 254:400-6.

10. Lind I, Bollerup AC, Colding $H$, Odum L. Activities of the WHO collaborating centre for reference and research in gonococci, Copenhagen, for the year 1979. WHO/VDT/RES/GON/80.130. Geneva: World Health Organisation, 1980: 1-13.

11. Ripa KT, Mărdh P-A. Cultivation of Chlamydia trachomatis in cycloheximide-treated McCoy cells. J Clin Microbiol 1977; 6:328-31

12. Reimann $\mathrm{K}$, Lind $\mathbf{I}$. An indirect haemagglutination test for demonstration of gonococcal antibodies using gonococcal pili as antigen. Methodology and preliminary results. Acta Pathol Microbiol Scand [C] 1977:85: 115-22.

13. Treharne JD, Darougar S, Jones BR. Modification of the microimmunofluorescense test to provide a routine serodiagnostic test for chlamydial infection. J Clin Pathol 1977; 30:510-7

14. Wulff HR. Rational diagnosis and treatment. An introduction to clinical decision-making. 2nd ed. Oxford: Blackwell Scientific Publications, 1981:80-102.

15. Eschenbach DA, Buchanan TM, Pollock $\mathrm{H}$, et al. Polymicrobial etiology of acute pelvic inflammatory disease. $N$ Engl J Med 1975;293: 166-71.

16. Thompson S, Hager WD, Wang K-H, et al. The microbiology and therapy of acute pelvic inflammatory disease in hospitalized patients. Am J Obstet Gynecol 1980; 136: 179-86.

17. Sweet RL, Mills J, Hadley KW, et al. Use of laparoscopy to determine the microbiologic etiology of acute salpingitis. Am J Obstet Gynecol 1979; 134:68-74.

18. Bowie WR, Lee CK. Prediction of efficacy of antimicrobial agents in treatment of infections due to Chlamydia trachomatis. J Infect Dis 1978; 138:655-9.

19. Mårdh P-A, Zeeberg B. Toxic effect of sampling swabs and transportation test tubes on the formation of intracytoplasmic inclusions of Chlamydia trachomatis in McCoy cell cultures. British Journal of Venereal Diseases 1981; 57:268-72.

20. Mårdh P-A, Westrom L, Colleen S, Wolner-Hansen P. Sampling, specimen handling and isolation techniques in the diagnosis of chlamydial and other genital infections. Sex Transm Dis 1981; 8:280-5.

21. Svensson L, Westrom L, Ripa KT, Mårdh P-A. Differences in some clinical and laboratory parameters in acute salpingitis related to culture and clinical findings. Am J Obstet Gynecol 1980; 138: 1017-21. 